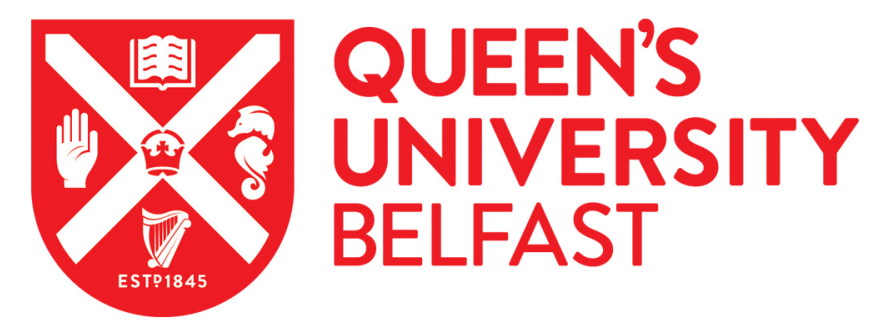

\title{
Strength model for end cover separation failure in RC beams strengthened with near-surface mounted (NSM) FRP strips
}

Teng, J. G., Zhang, S. S., \& Chen, J. F. (2016). Strength model for end cover separation failure in RC beams strengthened with near-surface mounted (NSM) FRP strips. Engineering Structures, 110, 222-232.

https://doi.org/10.1016/j.engstruct.2015.11.049

\section{Published in:}

Engineering Structures

Document Version:

Early version, also known as pre-print

Queen's University Belfast - Research Portal:

Link to publication record in Queen's University Belfast Research Portal

Publisher rights

(C) 2015, The Authors

\section{General rights}

Copyright for the publications made accessible via the Queen's University Belfast Research Portal is retained by the author(s) and / or other copyright owners and it is a condition of accessing these publications that users recognise and abide by the legal requirements associated with these rights.

Take down policy

The Research Portal is Queen's institutional repository that provides access to Queen's research output. Every effort has been made to ensure that content in the Research Portal does not infringe any person's rights, or applicable UK laws. If you discover content in the Research Portal that you believe breaches copyright or violates any law, please contact openaccess@qub.ac.uk. 


\title{
Strength Model for End Cover Separation Failure in RC Beams Strengthened with Near-surface Mounted (NSM) FRP Strips
}

\author{
J.G. Teng ${ }^{1, *}$, S.S. Zhang ${ }^{2}$ and J.F. Chen ${ }^{3}$ \\ ${ }^{1}$ Department of Civil and Environmental Engineering, The Hong Kong Polytechnic \\ University, Hong Kong, China. Email: cejgteng@ polyu.edu.hk \\ ${ }^{2}$ School of Civil, Mining \& Environmental Engineering, Faculty of Engineering \& \\ Information Sciences, University of Wollongong, Northfields Avenue, Wollongong, NSW \\ 2522, Australia. \\ ${ }^{3}$ School of Planning, Architecture and Civil Engineering, Queen's University Belfast, Belfast \\ BT9 5AG, UK
}

\begin{abstract}
As an alternative to externally bonded FRP reinforcement, near-surface mounted (NSM) FRP reinforcement can be used to effectively improve the flexural performance of RC beams. In such FRP-strengthened RC beams, end cover separation failure is one of the common failure modes. This failure mode involves the detachment of the NSM FRP reinforcement together with the concrete cover along the level of the steel tension reinforcement. This paper presents a new analytical strength model for end cover separation failure in RC beams strengthened in flexure with NSM FRP strips (i.e. rectangular FRP bars with a sectional height-to-thickness ratio not less than 5), which was formulated on the basis of extensive numerical results from a parametric study undertaken using an efficient finite element approach. The proposed strength model consists of an approximate analytical equation for the debonding strain of the FRP reinforcement at the critical cracked section and a conventional section analysis to relate this debonding strain to the moment acting on the same section (i.e. the debonding strain). Once the debonding strain is known, the load level at end cover separation of an FRP-strengthened RC beam can be easily determined for a given load distribution. Predictions from the proposed strength model are compared with those of two existing strength models of the same type and available test results, which shows that the proposed strength model is in close agreement with test results and is far more accurate than the existing strength models.
\end{abstract}

Keywords: End cover separation, finite element analysis, FRP strengthening, near-surface mounted (NSM) FRP, RC beams, strength model

* Corresponding author. Email: cejgteng@polyu.edu.hk; Fax: +852 2766 1354; Tel: +852 27666012 


\section{INTRODUCTION}

Extensive research has been undertaken on the flexural strengthening of reinforced concrete (RC) beams using bonded FRP reinforcement. Strengthening using externally bonded FRP reinforcement has received by far the largest amount of research [1-4], but the alternative of near-surface mounted (NSM) FRP reinforcement has also received increasing attention [e.g. 5-8]. The externally bonded FRP method involves the external bonding of FRP laminates, either formed in-situ via the wet layup process or prefabricated off site generally by pultrusion, to the tension surface of RC members, and the NSM FRP method involves the cutting of grooves in the cover concrete and the embedding of FRP bars in the grooves using an adhesive. FRP bars of various cross-sectional shapes can be used in NSM FRP strengthening of structures, including round, square, and rectangular bars [6]. As a special form of rectangular bars with a large cross-sectional height-to-thickness ratio, FRP strips are an attractive form of NSM FRP reinforcement due to their superior bond performance over NSM FRP bars of other shapes. This is because an FRP strip usually has a much larger perimeter for the same cross-sectional area than an FRP bar of other sectional shape and hence better bond performance, allowing a fuller utilization of the tensile strength of the FRP material [e.g. 9, 10]. Against this background, the present study is only concerned with NSM FRP strips which are defined as narrow rectangular FRP bars with a sectional height-to-thickness ratio not less than 5 [11]. For ease of presentation, the discussions in the paper are limited to simply supported beams.

In RC beams strengthened in flexure with NSM FRP bars, several debonding failure modes have been observed in laboratory tests, including end debonding failure and intermediate crack (IC) induced debonding failure. End cover separation (Fig. 1), as one of the end debonding failure modes, has been found to be by far the most common failure mode $[6,8]$. 
End cover separation failure process is initiated by the formation of a vertical crack in the un-strengthened region but near the critical end of the FRP reinforcement, followed by the propagation of a major crack at the level of the tension steel reinforcement towards the middle of the strengthened region. Another possible end debonding failure mode, namely interfacial debonding at the FRP-to-concrete interface, has been rarely if ever observed in laboratory tests [8]. A major reason that end cover separation is much more likely than end interfacial debonding is the significant radial stresses generated by the steel tension bars on the surrounding concrete, making the plane of steel tension bars a more critical plane than the plane near the adhesive-concrete bi-material interface [12].

For RC beams strengthened with externally bonded FRP reinforcement, a large number of finite element studies on end cover separation failure have been undertaken [e.g. 13-15] and several analytical strength models for this failure mode have been established [e.g. 16-19]. By contrast, for RC beams strengthened with NSM FRP reinforcement, very limited research has been conducted on finite element modelling $[12,20]$ or the establishment of strength models $[21,22]$ for the end cover separation failure mode. This situation is not surprising as the NSM FRP strengthening method emerged much later than the externally bonded FRP method and the associated research challenges are greater due to the presence of a large number of significant parameters.

To predict end cover separation failure in RC beams strengthened with NSM FRP reinforcement, a full 2-D (plane stress) nonlinear finite element (FE) approach (referred to as "the full FE approach" for brevity) has recently been developed by the authors [12, 20]. Using this full FE approach, the important factors that influence the accuracy of FE prediction of end cover separation failure have been identified. One of the factors is the radial 
stresses exerted by the steel tension reinforcement onto the surrounding concrete, which was introduced by the authors into FE modelling of end cover separation failure in RC beams strengthened with FRP for the first time $[12,20]$. Based on the findings from the full FE approach, a simplified 2-D (plane stress) FE approach (referred to as "the simplified FE approach" for brevity) $[23,24]$, in which only the part of the RC beam between the two adjacent cracks nearest to the critical end of the FRP reinforcement is included, was established for predicting end cover separation failure. This paper presents a study which was conducted using this simplified FE approach for the development of an analytical debonding strength model for RC beams strengthened with NSM FRP strips.

\section{EXISTING STRENGTH MODELS}

To date, only two strength models for end cover separation in RC beams strengthened in flexure with NSM FRP have been proposed [21, 22], and both of them are based on the concept of the so-called concrete tooth model (CTM) (Fig. 2). In a CTM, the "tooth" (Fig. 2), which is the concrete cover between two adjacent cracks, is treated as a cantilever, with the horizontal shear stress $\tau$ (from the NSM FRP) acting on its tip (i.e. free end). In addition to these two models, Hassan and Rizkalla [25] proposed a model based on interfacial stress analysis between NSM FRP strips and concrete to predict end interfacial debonding failure (another important end failure mode) in RC beams strengthened with NSM CFRP strips. For comparison purposes, Hassan and Rizkalla's model [25] is also introduced in this section although it deals with a slightly different failure mode.

\subsection{De Lorenzis and Nanni’s model [21]}

Based on Zhang et al.'s model (the first CTM for end cover separation) [26] for RC beams strengthened in flexure with an externally bonded steel plate, De Lorenzis and Nanni [21] 
proposed a strength model for end cover separation in RC beams strengthened in flexure with NSM FRP round bars. Assuming a linear elastic behaviour, the tensile stress $\sigma_{A}$ at the tension corner near the root of the concrete tooth (Point A in Fig. 2) can be calculated as

$$
\sigma_{A}=\frac{M_{A}}{I_{A}}\left(\frac{l}{2}\right)
$$

where $M_{A}=\tau n \pi d_{b} l h$ is the bending moment at the foot of the concrete tooth, $I_{A}=b l^{3} / 12$ is the sectional moment of area of the concrete tooth cross-section, $h^{\prime}$ is the vertical distance between the root of the concrete tooth and the centroid of the NSM FRP, $b$ is the width of the RC beam, $d_{b}$ is the diameter of the FRP round bar, $n$ is the number of the FRP bars, $\tau$ is the average interfacial shear stress between the NSM FRP bar and the concrete, and $l$ is either the minimum stabilized crack spacing, $l_{\min }$, or the maximum stabilized crack spacing, $l_{\max }=2 l_{\min }$. The minimum stabilized crack spacing $l_{\min }$ is given by

$$
l_{\text {min }}=\frac{A_{e} f_{t}}{u_{s} \sum O_{b a r s}+u_{N S M} \sum O_{N S M}}
$$

where $f_{t}=0.36 \sqrt{f_{c u}}$ (both $f_{t}$ and $f_{c u}$ are in $M P a$ ) is the concrete tensile strength while $f_{c u}$ is the concrete cube compressive strength; $\sum O_{b a r s}$ is the sum of perimeters of all the steel tension bars; $u_{s}=0.28 \sqrt{f_{c u}}$ (both $u_{s}$ and $f_{c u}$ are in $M P a$ ) is the average shear bond strength between steel bars and concrete; $\sum O_{N S M}$ is the sum of perimeters of all the NSM FRP round bars; $u_{N S M}$ is the bond strength between NSM FRP bars and concrete; $A_{e}=2 h_{1} b$ is the cross-sectional area of the concrete in the beam that is under tension, which is taken to be the product of twice the distance from the centroid of the tension steel to the soffit of the beam (i.e. $h_{1}$ ) and the beam width. De Lorenzis and Nanni [21] recommended that $u_{N S M}$ be taken as the local bond strength between NSM FRP bars and concrete. 
Substituting $M_{A}$ and $I_{A}$ into Eq. 1 and assuming that cover separation failure occurs when the tensile stress $\sigma_{A}$ is equal to the tensile strength of concrete $f_{t}$, the average interfacial shear stress $\tau_{\text {failure }}$ at failure can be found as

$$
\tau_{\text {failure }}=\frac{f_{t} l}{6 h^{\prime}} \frac{b}{n \pi d_{b}}
$$

The interfacial shear stress is balanced by the axial stress in the FRP. At the critical location (such as the loading point for three-point or four-point bending beams), the critical axial stress in the FRP can be found as

$$
\sigma_{\text {failure }}=\frac{4 \tau_{\text {failure }} L_{p}}{d_{b}}=\frac{2 \operatorname{lbf} f_{t} L_{P}}{3 n \pi h^{\prime} d_{b}^{2}}
$$

by assuming that the interfacial stress is uniformly distributed over the effective length of the NSM bars $L_{p}$. De Lorenzis and Nanni (2003) proposed the following expressions to estimate the effective length $L_{p}$ :

$$
\begin{array}{ccc}
L_{p}=\min \left(L_{p 1}, L_{p 2}\right) & \\
L_{p 2}=1.86 l_{\min }^{2}-127 l_{\text {min }}+2436 & \text { if } & l_{\text {min }} \leq 50 \mathrm{~mm} \\
L_{p 2}=736 & \text { if } & l_{\min }>50 \mathrm{~mm}
\end{array}
$$

where $L_{p 1}$ is the length of the NSM FRP bar in the shear span.

\subsection{Al-Mahmoud et al.'s model [22]}

Al-Mahmoud et al. [22] proposed a strength model of end cover separation in RC beams strengthened with NSM FRP round bars. Their model is also based on the general concept of the CTM, but the methodology is slightly different from that proposed by De Lorenzis and Nanni [21]. 
Al-Mahmoud et al. [22] related the bending moment at the root of the concrete tooth to the axial stress in the FRP bar at the left cracked section (i.e. the left vertical surface of the concrete tooth in Fig. 2, which is referred to as the critical cracked section in this paper) as

$$
M_{A}=\sigma_{f} A_{f} h^{\prime}=\sigma_{f} n \pi d_{b}^{2} h^{\prime}
$$

Combining Eqs. 1 and 7 and assuming that end cover separation occurs when the tensile stress $\sigma_{A}$ reaches the tensile strength of concrete $f_{t}$, the axial stress in the FRP bar at the critical cracked section can be expressed as

$$
\sigma_{f}=\frac{b_{c} l^{2}}{6 \pi n d_{b}^{2} h^{\prime}} f_{t}
$$

The axial stress in the FRP bar can be related to the bending moment $M_{l}$ of the strengthened beam at the critical cracked section as

$$
\sigma_{f}=n_{f}\left(\frac{h_{0}-y_{0}}{I_{c r}}\right) M_{l}
$$

where $n_{f}=E_{f} / E_{c}$ is the ratio of elastic modulus between FRP and concrete, $I_{c r}$ is the transformed second moment of area in terms of the concrete of the cracked section, $h_{0}$ is the distance between the compression face of the beam and the centroid of the NSM FRP reinforcement, and $y_{0}$ is the distance between the top surface of the beam and the neutral axis of the critical cracked section. Combining Eqs. 8 and 9 leads to the following expression for the bending moment of the strengthened beam at the left cracked section at cover separation failure:

$$
M_{l}=\frac{f_{t} I_{c r} b l^{2}}{6 n_{f} n \pi d_{b}^{2} h^{\prime}\left(h_{0}-y_{0}\right)}
$$




\subsection{Hassan and Rizkalla's model [25]}

Hassan and Rizkalla [25] established a model for the end interfacial debonding strength of RC beams strengthened with CFRP strips. Based on the interfacial stress analysis by Malek et al. [27] of RC beams strengthened with an externally bonded FRP plate, Hassan and Rizkalla [25] proposed a closed-form solution for the interfacial shear stress $\tau$ between the NSM CFRP strip and the concrete in RC beams strengthened with NSM CFRP strips, which leads to the following two equations for a simply supported beam subjected to 3-point bending (Eq. 11) and 4-point bending (Eq. 12) respectively:

$$
\begin{gathered}
\tau=\frac{t_{f}}{2}\left[\frac{n_{f} P a y_{\text {eff }}}{2 I_{\text {eff }}} \omega e^{-\omega x}+\frac{n_{f} P y_{\text {eff }}}{2 I_{\text {eff }}}\right] \\
\tau=\frac{t_{f}}{2}\left[\frac{n_{f} P y_{\text {eff }}}{I_{\text {eff }}}+\frac{n_{f} P y_{\text {eff }} a}{I_{\text {eff }}} \omega e^{-\omega x}\right] \\
\omega^{2}=\frac{2 G_{a}}{t_{a} t_{f} E_{f}}
\end{gathered}
$$

where $x$ is the distance from the critical end of the CFRP strip; $t_{f}$ is the thickness of the CFRP strip; $P$ is the concentrated load; $y_{\text {eff }}$ is the distance from the strip centroid to the neutral axis of the section; $I_{\text {eff }}$ is the effective second moment of area and can be calculated using Eq. 14; $e$ is the base of natural algorithm; $G_{a}$ is the shear modulus of the adhesive; $t_{a}$ is the thickness of the adhesive layer; and $a$ is the distance from the critical end of the NSM strip to the nearest support.

$$
I_{e f f}=\left(\frac{M_{c r}}{M_{a}}\right)^{3} I_{g}+\left(1-\left(\frac{M_{c r}}{M_{a}}\right)^{3}\right) I_{c r}
$$

where $M_{c r}$ and $M_{c r}$ are the cracking and the applied moments on a beam section, respectively; $I_{g}$ is the transformed gross second moment of area in terms of concrete of the 
strengthened section; and $I_{c r}$ is the transformed second moment of area in terms of concrete of the cracked section.

Obviously, the interfacial shear stresses calculated using Eqs. 11 and 12 achieve the largest values when $x$ is equal to zero (i.e. at the end of the FRP strip). By using the Mohr-Coulomb failure criterion, the interfacial shear stress at interfacial debonding failure of the FRP strip end, $\tau_{\max }$, can be determined from the following equation:

$$
\tau_{\max }=\frac{f_{c} f_{t}}{f_{c}+f_{t}}
$$

where $f_{c}$ is the concrete cylinder compressive strength; and $f_{t}$ is the concrete tensile strength. Substituting Eq. 15 into Eq. 11 or Eq.12 with $x=0$ yields the applied load at interfacial debonding failure of the FRP strip end.

\subsection{Summary}

As can be seen from the above review, in the end cover separation strength model proposed by Al-Mahmoud et al. [22] and the end interfacial debonding strength model proposed by Hassan and Rizkalla [25], the concrete is assumed to be a linear elastic material in compression; in De Lorenzis and Nanni's model [21], the concept of effective length of the NSM FRP is introduced, and in the effective length region, the interfacial stress is assumed to be uniformly distributed. In all three models, the bonded interface between FRP and concrete and that between steel bars and concrete are assumed to experience no interfacial slips. Despite these assumptions, which may lead to significant prediction errors, they represent valuable attempts at formulating strength models for end debonding failures in RC beams strengthened with NSM FRP reinforcement. 
In the present study, only Al-Mahmoud et al.'s model [22] and Hassan and Rizkalla's model [25] are compared with the present model. De Lorenzis and Nanni's model [21] was developed for NSM FRP round bars and cannot be easily adapted for use of NSM FRP strips. Although Al-Mahmoud et al.'s model [22] was originally proposed for RC beams strengthened with NSM round FRP bars, it can be easily modified for application to RC beams strengthened with NSM FRP strips: by replacing the formula for cross-sectional area for a circular section with that for a rectangular section.

When comparing Hassan and Rizkalla's model [25] with the present model in predicting end cover separation failure, it should be noted that the former is for end interfacial debonding while the latter is for end cover separation. However, it can be expected that the failure load predicted by Hassan and Rizkalla's model [25] should not be smaller than the test result as well as the prediction from the present model; otherwise, the beam should have failed by end interfacial debonding instead of end cover separation. The comparison thus can be used to check whether Hassan and Rizkalla's model [25] does provide an upper bound prediction.

\section{SIMPLIFIED FE APPROACH FOR END COVER SEPARATION}

The simplified FE model developed by Zhang and Teng $[23,24]$ for cover separation failure in FRP-strengthened RC beams was employed in a parametric study to generate numerical data for use in the formulation of a strength model. A brief summary of this simplified FE model is given herein to set the background for the parametric study. For more details of this simplified FE model, the reader is referred to Ref. [24].

In the simplified FE model, the segment of the RC beam between the two major cracks near the critical end of the FRP reinforcement is isolated to form the model for analysis (Fig. 3), 
with the moments acting on the two cracked sections being imposed using two pairs of external loads ( $\mathrm{R}$ and $\mathrm{P}_{3}$ as one pair on the critical, left cracked section, and $\mathrm{P}_{1}$ and $\mathrm{P}_{2}$ as another pair on the other cracked section at the FRP strip end in Fig. 3). A rigid plate is attached to each cracked section to enforce the plane section assumption. As can be seen from Fig. 3, if the strain in the FRP reinforcement at the critical crack (Point B in Fig. 3) at end cover separation is known, the moment acting on the same section can be obtained through section analysis. The concrete is modelled using 4-node plane stress elements; the steel reinforcement is simulated using 2-node beams elements and both sides of the steel reinforcement are connected to the rigid plates. The cohesive-element-pair (CEP) proposed by Zhang and Teng $[23,24]$ is used to simulate the radial stresses exerted by the tension steel bars onto the surrounding concrete when they are in tension. The FRP is modelled using 2-node beam elements located at the centroid of the NSM FRP reinforcement. Only one end (the left end in Fig. 3) of the FRP reinforcement is connected to the adjacent rigid plate, while the other end (the right end) representing the actual end of the FRP reinforcement and is left free.

The behaviour of cracked concrete is simulated using the orthogonal fixed smeared crack model. The crack band concept [28] is employed in the simplified FE model with the fracture energy being that given by CEB-FIP [29]. The maximum tensile stress criterion is adopted to describe the initiation of cracking while the yield surface proposed by Buyukozturk [30] with the associated flow rule is used to describe the compression-dominated behaviour of concrete. The tension-softening behaviour and the shear stress-slip behaviour of cracked concrete as well as the compressive behaviour of concrete are properly modelled. The FRP is modelled as an elastic isotropic brittle material, and the steel reinforcement including tension bars, compression bars and stirrups is modelled as an elastic-perfectly plastic material. The 
interfacial behaviour between longitudinal steel bars and concrete is simulated using the bond-slip model given in CEB-FIP 29] while that between NSM FRP strips and concrete is simulated using the bond-slip model proposed by Zhang et al. [31]. The latter means that the FE model is only applicable to RC beams strengthened in flexure with NSM CFRP strips although applicability to other forms of FRP reinforcement can be easily enabled by replacing Zhang et al.'s bond-slip model [31] with an appropriate model.

\section{STRENGTH MODEL FOR END COVER SEPARATION}

As explained earlier, if the strain in the FRP reinforcement at the critical cracked section (Point B in Fig. 3) at end cover separation failure (i.e. the debonding strain in the FRP or simply the debonding strain) can be obtained, a section analysis can be conducted to find the moment acting on the critical cracked section based on the plane section assumption, and the shear force and the load level of the beam can be easily found from the bending moment value for a given load distribution. The proposed debonding strength model for end cover separation failure thus consists of a method for predicting debonding strain and a conventional section analysis based on the plane section assumption, with the former being the key element. In the present study, the section analysis is based on the BS 8110 [32] compressive stress-strain curve of concrete, so the ultimate concrete compressive strain is taken to be 0.0035 .

\subsection{Debonding strain in the FRP at end cover separation}

The FE approach described earlier was used to conduct a parametric study to generate numerical results for the development of an approximate analytical equation for the debonding strain. The following geometric and material properties define the reference case for the parametric study unless otherwise specified: concrete cylinder compressive strength 
$f_{c}=30 \mathrm{MPa}$; elastic modulus of FRP $E_{f}=150 \mathrm{GPa} ; A_{f}=40 \mathrm{~mm}^{2}$; thickness of FRP strip = $2 \mathrm{~mm}$; second moment of area of FRP strip $I_{f}=1333 \mathrm{~mm}^{4}$; vertical distance between the centroids of the steel and the FRP reinforcements $c_{d}=30 \mathrm{~mm}$; crack spacing $s_{c}=100 \mathrm{~mm}$ (length of the beam segment in the FE model); height of the beam $h=300 \mathrm{~mm}$; width of the beam $b=150 \mathrm{~mm}$; sum of diameters of all steel tensions bars $D_{t}=24 \mathrm{~mm}$ (i.e. $2 \phi 12$ ); and moment ratio between the right and the left cracked sections $\beta_{P}=0.5$.

\subsubsection{Effect of second moment of area of FRP strip}

The second moment of area of the FRP strip, $\boldsymbol{I}_{f}$, was varied from $1 \times 10^{3} \mathrm{~mm}^{4}$ to $2 \times 10^{4} \mathrm{~mm}^{4}$ to examine its effect on the debonding strain. The cross-sectional area of the FRP strip was kept constant at $40 \mathrm{~mm}^{2}$, but the height and thickness of the FRP strip cross-section were changed to achieve the desired $I_{f}$ value. Note that for the reference beam with a width of $150 \mathrm{~mm}, I_{f}=5 \times 10^{3} \mathrm{~mm}^{4}$, which is a practically likely value (e.g. $I_{f}=5.2 \times 10^{3} \mathrm{~mm}^{4}$ for two $2 \times 25 \mathrm{~mm}$ NSM CFRP strips). Therefore, the selected range of $I_{f}$ values was large enough to cover practical situations and to examine its influence.

The predicted debonding strains are listed in Table 1 . The maximum difference between the predicted FRP strains is only about $2 \%$ within the range of $I_{f}$ values investigated, so it may be concluded that for practical applications, the effect of $I_{f}$ is minimal and can be neglected.

\subsubsection{Effect of beam height}

Table 2 provides the predicted debonding strains for three beam heights: $h=300 \mathrm{~mm}, 600$ 
$\mathrm{mm}$, and $900 \mathrm{~mm}$; all other properties are the same as those of the reference case. Clearly the effect of beam height is also insignificant, so it can also be neglected in evaluating the debonding strain in the FRP.

\subsubsection{Effect of moment ratio}

The effect of moment ratio $\beta_{P}$ was examined for three different concrete strengths $\left(f_{c}=20\right.$ $M P a, 30 \mathrm{MPa}$ and $40 \mathrm{MPa}$ ), four values of the distance between the steel and the FRP reinforcements $\left(c_{d}=15 \mathrm{~mm}, 30 \mathrm{~mm}, 45 \mathrm{~mm}\right.$, and $60 \mathrm{~mm}$ ), and four different crack spacings $\left(s_{c}=50 \mathrm{~mm}, 75 \mathrm{~mm}, 100 \mathrm{~mm}\right.$, and $\left.150 \mathrm{~mm}\right)$. In each case, the moment ratio between the right and the left cracked sections was varied from 0 to 1.0 at an interval of 0.1 . The predicted debonding strains, normalized with respect to the debonding strain of the corresponding case with a moment ratio of 0.6 , are shown in Fig. 4. For ease of reference, each numerical case (or numerical specimen) in Fig. 4 is given a name, which starts with a number to represent the cylinder compressive strength of concrete $\left(f_{c}\right)$, followed by a number to represent the elastic modulus of FRP ( $E_{f}$ ), and then a number to represent the distance between steel and FRP reinforcements $\left(c_{d}\right)$, and finally a number to represent the crack spacing $\left(s_{c}\right)$. It is seen that as the moment ratio increases, the debonding strain first increases nearly linearly regardless of the values of the other parameters (i.e. $f_{c}, c_{d}$ and $s_{c}$ ) until the moment ratio reaches 0.6; afterwards, the debonding strain decreases nearly linearly. All of the normalized curves shown in Fig. 4 are almost identical to each other, with most values falling in the range from 0.9 to 1 . The effect of moment ratio on the debonding strain is therefore small and is ignored in the approximate predictive equation for debonding strain presented later in the paper. 


\subsubsection{Effect of axial rigidity of FRP strip}

The axial rigidity of the FRP strip $A_{f} E_{f}$ was varied from $2000 \mathrm{kN}\left(20 \mathrm{~mm}^{2} \times 100 \mathrm{GPa}\right)$ to $16000 \mathrm{kN}\left(80 \mathrm{~mm}^{2} \times 200 \mathrm{GPa}\right)$ to study its effect on the debonding strain. The relationship between the FRP debonding strain obtained from FE analysis and the reciprocal of FRP axial rigidity $A_{f} E_{f}$ is plotted in Fig. 5, from which it can be seen that the variation of the FE debonding strain with the reciprocal of FRP strip axial rigidity follows approximately a power function.

\subsubsection{Effect of concrete strength}

The effect of concrete strength $f_{c}$ was examined for three different values of the elastic modulus of FRP $\left(E_{f}=100 \mathrm{GPa}, 150 \mathrm{GPa}\right.$, and $200 \mathrm{GPa}$ ) and four different values of the cross-sectional area of FRP strip $\left(A_{f}=20 \mathrm{~mm}^{2}, 40 \mathrm{~mm}^{2}, 60 \mathrm{~mm}^{2}\right.$ and $80 \mathrm{~mm}^{2}$ ). The other geometric and material properties of the beams were the same as those of the reference beam. The predicted relationship between the debonding strain and the concrete strength is shown in Fig. 6, which indicates that the FRP strain is approximately proportional to $\sqrt{f_{c}}$. Each numerical specimen in Fig. 6 is given a name, which starts with a number to represent the elastic modulus of FRP $\left(E_{f}\right)$ and is then followed by a number to represent the cross-sectional area of FRP strip $\left(A_{f}\right)$.

\subsubsection{Effects of crack spacing and distance between steel and FRP reinforcements}

The effect of distance between steel reinforcement and FRP reinforcements, $c_{d}$, was examined by obtaining FE predictions for four different values: $15 \mathrm{~mm}, 30 \mathrm{~mm}, 45 \mathrm{~mm}$, and $60 \mathrm{~mm}$. The effect of crack spacing, $s_{c}$, was also examined by obtaining FE predictions for 
four different values: $50 \mathrm{~mm}, 75 \mathrm{~mm}, 100 \mathrm{~mm}$, and $150 \mathrm{~mm}$. The relationship between the debonding strain and $c_{d}$ is shown in Fig. 7 while that between the debonding strain and $s_{c}$ is shown in Fig. 8. Fig. 7 indicates that the debonding strain decreases nearly linearly as the value of $c_{d}$ increases, with the slopes of the linear best-fit lines for different $s_{c}$ values being nearly the same. Fig. 8 indicates that the debonding strain increases with the value of $s_{c}$. As the value of $c_{d}$ increases, the relationship between the debonding strain and $s_{c}$ changes from a power function to a linear function. To see a clearer trend, the debonding strains normalized with respect to the strain of the case with a $c_{d}$ value of $30 \mathrm{~mm}$ are shown in Fig. 9, which indicates that the normalized strain decreases nearly linearly as the value of $c_{d}$ increases regardless of the values of $s_{c}$ and the magnitude of slope of the linear best-fit lines decreases as the value of $s_{c}$ increases.

\subsubsection{Effects of beam width and sum of steel tension bar diameters}

The debonding strain in the FRP is expected to be proportional to the clear width of the beam $b_{\text {clear }}=b-D_{t}$, where $D_{t}$ is the sum of all steel tension bar diameters, if other parameters are the same. Furthermore, the debonding strain is expected to depend on the $b_{\text {clear }} / \mathrm{D}_{t}$ ratio as the effect of radial stresses from steel tension bars is affected by the $b_{\text {clear }} / \mathrm{D}_{t}$ ratio. In the parametric study, the following beam widths were examined: $50 \mathrm{~mm}, 100 \mathrm{~mm}, 150 \mathrm{~mm}, 200$ $m m$, and $250 \mathrm{~mm}$, with the corresponding $b_{\text {clear }} / \mathrm{D}_{t}$ ratios being $1.08,3.17,5.25,7.33$ and 9.42. The corresponding values chosen for the cross-sectional area of the FRP strip, $A_{f}$, are $8.25 \mathrm{~mm}^{2}, 24.13 \mathrm{~mm}^{2}, 40.00 \mathrm{~mm}^{2}, 55.88 \mathrm{~mm}^{2}$ and $71.75 \mathrm{~mm}^{2}$, in order to keep the 
ratio constant. Fig. 10 shows that the predicted debonding strain increases with the $b_{\text {clear }} / \mathrm{D}_{t}$ ratio approximately following a power function.

\subsubsection{Approximate equation for the debonding strain}

Based on the regression analysis of the results of 168 numerical specimens examined in the parametric study, Eq. 16 is proposed as a design model for predicting the debonding strain in the FRP at end cover separation failure:

$$
\begin{gathered}
\varepsilon_{d b}=10^{4} \times \beta_{c s} \beta_{A E} \beta_{b o d} b_{\text {clear }} \sqrt{f_{c}} \\
\beta_{c s}=\left(\frac{4.5}{s_{c}^{0.3}}-\frac{c}{s_{c}}\right)\left(\frac{s_{c}}{100}-0.1\right) \\
\beta_{A E}=\frac{1}{\left(A_{f} E_{f}\right)^{0.9}} \\
\beta_{b o d}=\left(\frac{b_{\text {clear }}}{D_{t}}\right)^{0.1}
\end{gathered}
$$

where $\beta_{c s}$ reflects the combined effect of $c_{d}$ (distance between the steel and the FRP reinforcements, in $\mathrm{mm}$ ) and $s_{c}$ (crack spacing, in $\mathrm{mm}$ ); $\beta_{A E}$ reflects the effect of axial rigidity of FRP strip $A_{f} E_{f}$ ( $A_{f}$ in $m^{2}$ and $E_{f}$ in $G P a$ ); and $\beta_{b o d}$ reflects the effect of ratio between beam clear width $b_{\text {clear }}$ (in $\mathrm{mm}$ ) and sum of steel tension bar diameters $\mathrm{D}_{t}$ (in $\mathrm{mm}$ ). The concrete cylinder strength $f_{c}$ is in $M P a$.

A comparison between the predictions of the simplified FE model and the analytical debonding strain equation (Eq. 16) is shown in Fig. 11, indicating very close agreement between the two sets of results. The ratios between the analytical and the FE predictions have an average value of 1.00, a standard deviation (STD) of 0.070 and a coefficient of variation 
$(\mathrm{CoV})$ of 0.070 .

\subsection{Crack spacing}

To determine the debonding strain as well as the distance between the left cracked section and the nearest support, the crack spacing is needed as input. In the present study, the minimum stabilized crack spacing, $s_{c}^{\min }$, proposed by Zhang et al. [26] is adopted:

$$
s_{c}^{\min }=\frac{A_{e} f_{t}}{u_{s} \sum O_{\text {bars }}+u_{f} C_{\text {failure }}}
$$

where $u_{f}=0.28 \sqrt{f_{c u}}$ is the average shear bond strength between FRP and concrete, $C_{\text {failure }}$ is the perimeter length of the failure plane which is taken to be the total length of the three groove sides. In the next section, the minimum stabilized crack spacing, $s_{c}^{\text {min }}$, the maximum stabilized crack spacing, $2 s_{c}^{\min }$, and an intermediate value, $1.5 s_{c}^{\min }$, are all examined to investigate the effect of crack spacing.

\section{COMPARISON WITH TEST DATA}

For the proposed debonding strain equation for end cover separation to be used with confidence in practical design, its accuracy needs to be assessed using laboratory test data. The test data of $10 \mathrm{RC}$ beams strengthened with NSM FRP strips were collected from the published literature for this purpose. For all these 10 beams, sufficient details have been provided in the papers for them to be used in the comparison. Details of these 10 test beams are given in Tables 3 and 4. In addition to the present debonding strength model, the models of Al-Mahmoud et al. [22] and Hassan and Rizkalla [25] are also included in the comparison.

The predictions of the present debonding strength model for three different crack spacings 
(i.e. $s_{c}=s_{c}^{\min }, 1.5 s_{c}^{\min }$ and $2 s_{c}^{\min }$ respectively) are compared in Fig. 12 with the test results. The predictions of the two existing models for these $10 \mathrm{RC}$ beams are compared with the test results in Figs. 13 and 14 respectively. All the analytical predictions and the test results for the shear force are listed in Tables 5.

The proposed strength model with a crack spacing of $1.5 s_{c}^{\min }$ leads to an average prediction-to-test ratio of 1.10 , a STD of 0.119 and a CoV of 0.108 (Table 5). These statistical indicators are better than those for predictions of the proposed strength model obtained with crack spacings of $s_{c}^{\min }$ and $2 s_{c}^{\min }$, for which the average prediction-to-test ratios are 0.863 and 1.17, the STDs are 0.155 and 0.172 , and the CoVs are 0.180, 0.147 respectively. Nevertheless, the proposed strength model with any of the three crack spacing values offers much closer predictions of the test results than the two existing models proposed by Al-Mahmoud et al. [22] and Hassan and Rizkalla [25] respectively. The predictions from Hassan and Rizkalla's model [25] are very conservative with a large scatter, with the prediction-to-test average ratio, STD and $\mathrm{CoV}$ being $0.555,0.259$ and 0.467 respectively, indicating that Hassan and Rizkalla's model [25] fails to provide a reasonable upper bound prediction. The predictions of Al-Mahmoud et al.'s model [22], on the contrary, are very un-conservative with an even larger scatter, with the average prediction-to-test ratio, STD and $\mathrm{CoV}$ being 1.90, 1.34 and 0.702 respectively. The superior performance of the proposed debonding strength model is also clearly demonstrated by the comparisons given in Figs. 12 to 14 .

\section{CONCLUDING REMARKS}

This paper has been concerned with the development of an analytical model for predicting the end cover separation failure load of RC beams strengthened with FRP strips (i.e. rectangular 
FRP bars with a sectional height-to-thickness ratio not less than 5). The approach taken was to develop an analytical equation for the debonding strain in the FRP strips at the critical cracked section at end cover separation failure (i.e. the debonding strain) and to find the moment acting in the critical cracked section by conventional section analysis based on the plane section assumption (i.e. the debonding moment). Once the debonding moment is known, the associated shear force and the load level at cover separation failure can be easily determined for any given load distribution. The analytical equation for the debonding strain is thus the key element of the proposed debonding strength model. In practice, the alternative approach of checking the strain in the FRP strips at the critical cracked section against the prediction of the proposed debonding strain equation can be adopted to design again cover separation failure.

To formulate an analytical equation for the debonding strain, an efficient FE approach recently proposed by the authors $[23,24]$ was employed in a parametric study to obtain extensive numerical results. These results were presented and examined to understand how each parameter affects this debonding strain, based on which an appropriate analytical equation for the debonding strain was proposed. The proposed strength model as well as with two existing strength models for end debonding failure was compared with a test database assembled from the published literature. These comparisons showed that the proposed strength model leads to predictions in close agreement with the test results and is far more accurate than the two existing models.

\section{ACKNOWLEDGEMENT}

The authors are grateful for the financial support received from the Research Grants Council of the Hong Kong Special Administrative Region (Project Nos: PolyU 5315/09E), the 
National Basic Research Program of China (“973” Program) (Project No.: 2012CB026201) and the National Natural Science Foundation of China (Project No. 51308483).

\section{REFERENCES}

[1] Teng, J. G., Chen, J. F., Smith, S. T., and Lam, L. (2002). FRP-strengthened RC Structures, West Sussex: Wiley.

[2] Oehlers, D. J. and Seracino, R. (2004). Design of FRP and steel plated RC structures: retrofitting beams and slabs for strength, stiffness and ductility. Elsevier.

[3] Bank L.C. (2006). Composites for construction: Structural design with FRP materials. West Sussex: Wiley, UK.

[4] Hollaway, L. C. and Teng, J. G., eds. (2008). Strengthening and rehabilitation of civil infrastructures using FRP composites, Woodhead, Cambridge, U.K.

[5] Barros, J. A. O., Dias, S. J. E., and Lima, J. L. T. (2007). "Efficacy of CFRP-based techniques for the flexural and shear strengthening of concrete beams." Cement \& Concrete Composites, 29(3), 203-217.

[6] De Lorenzis, L. and Teng, J. G. (2007). "Near-surface mounted FRP reinforcement: an emerging technique for strengthening structures." Composites: Part B, 38(2), 119-143.

[7] Soliman, S.M., El-Salakawy, E. and Benmokrane, B. (2011). "Bond performance of near-surface-mounted FRP bars.” Journal of Composites for Construction, ASCE, 15(1), 103-111.

[8] Zhang, S. S. (2012). Behaviour and modelling of RC beams strengthened in flexure with near-surface mounted FRP strips. PhD thesis, The Hong Kong Polytechnic University, Hong Kong, China.

[9] El Hacha, R. and Rizkalla, S.H. (2004). "Near-surface-mounted fiber-reinforced polymer reinforcements for flexural strengthening of concrete structures." $A C I$ 
Structural Journal, 101(5), 717-726.

[10] Perera, W.K.K.G., Ibell, T.J. and Darby, A. P. (2009). "Bond behaviour and effectiveness of various shapes of NSM CFRP bars." Proceedings, 9th International Symposium on Fiber-Reinforced Polymers Reinforcement for Concrete Structures (FRPRCS-9), 13-15 July, Sydney, Australia (CD-ROM).

[11] Zhang, S. S., Teng, J. G. and Yu, T. (2014). "Bond strength model for CFRP strips near-surface mounted to concrete." Journal of Composites for Construction, ASCE, 18, SPECIAL ISSUE: 10th Anniversary of IIFC, A4014003.

[12] Zhang, S.S. and Teng, J.G. (2014). "Finite element analysis of end cover separation in RC beams strengthened in flexure with FRP”, Engineering Structures, 75, 550-560.

[13] Arduini, M., Tommaso, A. D., and Nanni, A. (1997). "Brittle failure in FRP plate and sheet bonded beams.” ACI Structural Journal 94(4), 363-370.

[14] Rahimi, H. and Hutchinson, A. (2001). "Concrete beams strengthened with externally bonded FRP plates.” Journal of Composites for Construction, ASCE, 5(1), 44-56.

[15] Pham, H.B. and Al-Mahaidi, R. (2005) "Finite element modelling of RC beams retrofitted with CFRP fabrics." Proceedings, 7th International Symposium on Fiber Reinforced Polymer Reinforcement for Reinforced Concrete Structures, American Concrete Institute 2005, SP-230, 499-514.

[16] Oehlers, D. J. (1992). "Reinforced-concrete beams with plates glued to their soffits." Journal of Structural Engineering, ASCE, 118(8), 2023-2038.

[17] Oehlers, D. J., Liu, I. S. T., Seracino, R. and Ali, M. S. M. (2004). "Prestress model for shear deformation debonding of FRP- and steel-plated RC beams." Magazine of Concrete Research, 56(8), 475-486.

[18] Gao, B., Leung, C. K. Y. and Kim, J. K. (2005). "Prediction of concrete cover separation failure for RC beams strengthened with CFRP strips." Engineering 
Structures, 27(2), 177-189.

[19] Teng, J. G. and Yao, J. (2007). "Plate end debonding in FRP-plated RC beams-II: strength model.” Engineering Structures, 29(10), 2472-2486.

[20] Zhang, S. S. and Teng, J. G. (2010). "Finite element prediction of plate-end cover separation in FRP-strengthened RC beams." Proceedings, 11th International Symposium on Structural Engineering, December 18-20, 2010, Guangzhou, China, pp. 1794-1799.

[21] De Lorenzis, L. and Nanni, A. (2003). "Proposed design procedure of NSM FRP reinforcement for strengthening of RC beams." Proceedings, 6th International Symposium on FRP Reinforcement for Concrete Structures, July 8-10, 2003, Singapore, pp. $1455-1464$.

[22] Al-Mahmoud, F., Castel, A., Francois, R., and Tourneur, C. (2010). "RC beams strengthened with NSM CFRP rods and modeling of peeling-off failure." Composite Structures, 92(8), 1920-1930.

[23] Zhang, S.S. and Teng, J.G. (2013). "Simplified finite element modelling of end cover separation in RC beams flexurally-strengthened with bonded FRP reinforcement." Proceedings, 4th Asia Pacific Conference on FRP Composites in Structures (APFIS), December, 11-13, 2013, Melbourne, Australia. (CD-ROM).

[24] Zhang, S.S. and Teng, J.G. (2015). "End cover separation in RC beams strengthened in flexure with bonded FRP reinforcement: simplified finite element approach.” Materials and Structures, accepted for publication.

[25] Hassan, T. K. and Rizkalla, S. H. (2003). "Investigation of bond in concrete structures strengthened with near surface mounted carbon fiber reinforced polymer strips." Journal of Composites for Construction, ASCE, 7(3), 248-257.

[26] Zhang, S., Raoof, M. and Wood, L. A. (1995). "Prediction of peeling failure of 
reinforced-concrete beams with externally bonded steel plates." Proceedings, the Institution of Civil Engineers-Structures and Buildings, 110(3), 257-268.

[27] Malek, A. M., Saadatmanesh, H. and Ehsani, M. R. (1998). "Prediction of failure load of R/C beams strengthened with FRP plate due to stress concentration at the plate end." ACI Structural Journal, 95(1), 142-152.

[28] Bazant, Z.P. and Oh, B.H. (1983). "Crack band theory for fracture of concrete." Materials and Structures, 16(93), 155-177.

[29] CEB-FIP. (1993). Model Code 90, Lausanne, Switzerland.

[30] Buyukozturk, O. (1997). "Nonlinear analysis of reinforced concrete structures." Computers and Structures , 7, 149-156.

[31] Zhang, S.S., Teng, J.G. and Yu, T. (2013). "Bond-slip model for CFRP strips near-surface mounted to concrete." Engineering Structures, 56, 945-953.

[32] BS 8110. (1997). Structural use of concrete-part 1: Code of practice for design and construction, London: British Standards Institute, UK.

[33] Barros, J. A. O. and Fortes, A. S. (2005). "Flexural strengthening of concrete beams with CFRP laminates bonded into slits." Cement \& Concrete Composites, 27(4), 471-480.

[34] Teng, J. G., De Lorenzis, L., Wang, B., Rong, L., Wong, T. N. and Lam, L. (2006). "Debonding failures of RC beams strengthened with near-surface mounted CFRP strips." Journal of Composites for Construction, ASCE, 10(2), 92-105.

[35] Thorenfeldt, E. (2007). "Bond capacity of CFRP strips glued to concrete in sawn slits." Proceedings, 8th International Conference on Fibre Reinforced Plastics for Reinforced Concrete Structures, July 16-18, 2007, Patras, Greece (CD-ROM). 


\section{TABLES}

Table 1. Effect of second moment of area of FRP bar on debonding strain

\begin{tabular}{c|c|c}
\hline $\begin{array}{c}\text { Second moment of area of } \\
\text { FRP bar } \\
I_{f}\left(\mathrm{~mm}^{4}\right)\end{array}$ & $\begin{array}{c}\text { Debonding strain } \varepsilon_{d b} \\
(\mu \varepsilon)\end{array}$ & Percentage reduction \\
\hline $1 \times 10^{3}$ & 2483 & $0.00 \%$ \\
\hline $5 \times 10^{3}$ & 2472 & $0.44 \%$ \\
\hline $1 \times 10^{4}$ & 2455 & $1.13 \%$ \\
\hline $2 \times 10^{4}$ & 2435 & $1.93 \%$ \\
\hline
\end{tabular}

Table 2. Effect of beam height on debonding strain

\begin{tabular}{c|c|c}
\hline $\begin{array}{c}\text { Beam height } \\
h(\mathrm{~mm})\end{array}$ & $\begin{array}{c}\text { Debonding strain } \varepsilon_{d b} \\
(\mu \varepsilon)\end{array}$ & Percentage reduction \\
\hline 300 & 2482 & $0.00 \%$ \\
\hline 600 & 2453 & $1.17 \%$ \\
\hline 900 & 2416 & $2.66 \%$ \\
\hline
\end{tabular}

Table 3. Details of RC beams strengthened with NSM FRP

\begin{tabular}{|c|c|c|c|c|c|c|c|c|c|}
\hline Source & Specimen & $\begin{array}{c}b \\
(\mathrm{~mm})\end{array}$ & $\begin{array}{c}h \\
(\mathrm{~mm})\end{array}$ & $\begin{array}{c}h_{0} \\
(\mathrm{~mm})\end{array}$ & $\begin{array}{c}a \\
(\mathrm{~mm})\end{array}$ & $\begin{array}{c}a_{v} \\
(\mathrm{~mm})\end{array}$ & $\begin{array}{c}L \\
(\mathrm{~mm})\end{array}$ & $\begin{array}{c}f_{c} \\
(M P a)\end{array}$ & $\begin{array}{c}E_{c} \\
(G P a)\end{array}$ \\
\hline \multirow{3}{*}{ Ref. [33] } & V2R2 & 100 & 177 & 157 & 50 & 500 & 1500 & 46.1 & 32.1 \\
\hline & V3R2 & 100 & 175 & 155 & 50 & 500 & 1500 & 46.1 & 32.1 \\
\hline & V4R3 & 100 & 180 & 160 & 50 & 500 & 1500 & 46.1 & 32.1 \\
\hline \multirow{3}{*}{ Ref. [34] } & B500 & 150 & 300 & 256 & 1200 & 1200 & 3000 & 35.2 & 28.1 \\
\hline & B1200 & 150 & 300 & 256 & 900 & 1200 & 3000 & 35.2 & 28.1 \\
\hline & B1800 & 150 & 300 & 256 & 600 & 1200 & 3000 & 35.2 & 28.1 \\
\hline \multirow{2}{*}{ Ref. [5] } & S2 & 120 & 170 & 146 & 60 & 300 & 900 & 52.2 & 34.2 \\
\hline & S3 & 120 & 170 & 146 & 60 & 300 & 900 & 52.2 & 34.2 \\
\hline \multirow{2}{*}{ Ref. [35] } & B2 & 150 & 250 & 206 & 100 & 950 & 2500 & 50.0 & 33.4 \\
\hline & B5 & 150 & 250 & 206 & 100 & 950 & 2500 & 50.0 & 33.4 \\
\hline
\end{tabular}

Note: $b=$ width of beam; $h=$ height of beam; $h_{0}=$ effective depth of beam; $a=$ distance from a bar end to the nearest support; $a_{v}=$ shear span of beam; $L=$ span of beam; $f_{c}=$ cylinder compressive strength of concrete; and $E_{c}=$ elastic modulus of concrete. 
Table 4. Details of steel bars and FRP strips for the test beams

\begin{tabular}{|c|c|c|c|c|c|c|c|c|c|c|c|c|c|c|c|c|c|}
\hline Source & Specimen & $\begin{array}{c}E_{f} \\
(G P a)\end{array}$ & $\begin{array}{c}f_{f} \\
(M P a)\end{array}$ & $\begin{array}{c}\boldsymbol{t}_{f} \\
(\mathrm{~mm})\end{array}$ & $\begin{array}{c}h_{f} \\
(m m)\end{array}$ & $\begin{array}{c}E_{s}^{t e n} \\
(G P a)\end{array}$ & $\begin{array}{c}f_{y}^{\text {ten }} \\
(G P a)\end{array}$ & $\begin{array}{c}A_{s}^{\text {ten }} \\
\left(m m^{2}\right)\end{array}$ & $(n / \phi)_{t e n}$ & $\begin{array}{c}E_{s}^{c o m} \\
(G P a)\end{array}$ & $\begin{array}{c}f_{y}^{c o m} \\
(G P a)\end{array}$ & $\begin{array}{l}A_{s}^{c o m} \\
\left(m m^{2}\right)\end{array}$ & $(n / \phi)_{c o m}$ & $\begin{array}{c}E_{\mathrm{vc}} \\
(G P a)\end{array}$ & $\begin{array}{c}f_{\mathrm{vy}} \\
(G P a)\end{array}$ & $\begin{array}{c}A_{\mathrm{vc}} \\
\left(m m^{2}\right)\end{array}$ & $\begin{array}{c}S_{\mathrm{v}} \\
(\mathrm{mm})\end{array}$ \\
\hline \multirow{3}{*}{ Ref. [33] } & V2R2 & 158.8 & 2739.5 & 2.9 & 9.59 & 200 & 730 & 84.8 & $3 / 6$ & 200 & 730 & 101 & $2 / 8$ & 200 & 730 & 56.5 & 100 \\
\hline & V3R2 & 158.8 & 2739.5 & 2.9 & 9.59 & 200 & 730 & 107 & $2 / 6+1 / 8$ & 200 & 730 & 101 & $2 / 8$ & 200 & 730 & 56.5 & 100 \\
\hline & V4R3 & 158.8 & 2739.5 & 4.35 & 9.59 & 200 & 730 & 151 & $3 / 6$ & 200 & 730 & 101 & $2 / 8$ & 200 & 730 & 56.5 & 100 \\
\hline \multirow{3}{*}{ Ref. [34] } & B500 & 151 & 2068 & 4 & 16 & 210 & 532 & 226 & $2 / 12$ & 210 & 375 & 101 & $2 / 8$ & 210 & 375 & 101 & 100 \\
\hline & B1200 & 151 & 2068 & 4 & 16. & 210 & 532 & 226 & $2 / 12$ & 210 & 375 & 101 & $2 / 8$ & 210 & 375 & 101 & 100 \\
\hline & B1800 & 151 & 2068 & 4 & 16 & 210 & 532 & 226 & $2 / 12$ & 210 & 375 & 101 & $2 / 8$ & 210 & 375 & 101 & 100 \\
\hline \multirow{2}{*}{ Ref. [5] } & S2 & 158.8 & 2740 & 2.8 & 9.6 & 200 & 627 & 66.4 & $2 / 6.5$ & 200 & 627 & 66.4 & $2 / 6.5$ & 200 & 540 & 56.5 & 80 \\
\hline & S3 & 158.8 & 2740 & 4.2 & 9.6 & 200 & 627 & 99.5 & $3 / 6.5$ & 200 & 627 & 66.4 & $2 / 6.5$ & 200 & 540 & 56.5 & 80 \\
\hline \multirow{2}{*}{ Ref. [35] } & $\mathrm{B} 2$ & 157 & 2580 & 6 & 15 & 203 & 530 & 226 & $2 / 12$ & 203 & 530 & 226 & $2 / 12$ & 200 & 530 & 101 & 100 \\
\hline & B5 & 153 & 2500 & 5 & 20 & 203 & 530 & 226 & $2 / 12$ & 203 & 530 & 226 & $2 / 12$ & 200 & 530 & 101 & 100 \\
\hline
\end{tabular}

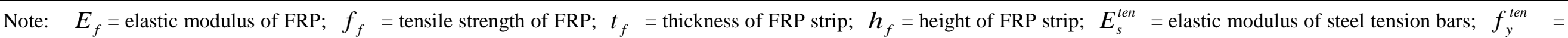

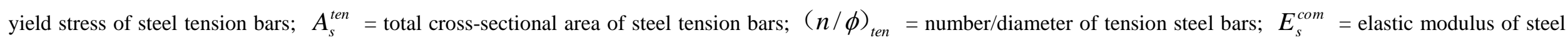

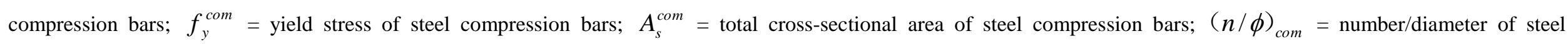
compression bars; $E_{\mathrm{vc}}=$ elastic modulus of stirrups; $f_{\mathrm{vy}}=$ yield stress of stirrups; $A_{\mathrm{vc}}=$ total cross-sectional area of stirrups; $S_{\mathrm{v}}=$ spacing of stirrups. 
Table 5. Test and predicted ultimate shear forces for beams strengthened with NSM FRP

\begin{tabular}{|c|c|c|c|c|c|c|c|c|c|c|c|c|}
\hline Source & Specimens & $\begin{array}{l}V_{\text {test }} \\
(k N)\end{array}$ & $\begin{array}{c}V_{p r e, 1} \\
(k N)\end{array}$ & $\frac{V_{\text {pre }, 1}}{V_{\text {test }}}$ & $\begin{array}{c}V_{p r e, 1.5} \\
(k N)\end{array}$ & $\frac{V_{\text {pre }, 1.5}}{V_{\text {test }}}$ & $\begin{array}{c}V_{p r e, 2} \\
(k N)\end{array}$ & $\frac{V_{\text {pre, } 2}}{V_{\text {test }}}$ & $\begin{array}{l}V_{H-R} \\
(k N)\end{array}$ & $\frac{V_{H-R}}{V_{\text {test }}}$ & $\begin{array}{c}V_{A I} \\
(k N)\end{array}$ & $\frac{V_{A I}}{V_{\text {test }}}$ \\
\hline \multirow{3}{*}{ Ref. [33] } & V2R2 & 39.25 & 40.7 & 1.04 & 50.3 & 1.28 & 55.3 & 1.41 & 34.7 & 0.884 & 143 & 3.64 \\
\hline & V3R2 & 40.95 & 43.2 & 1.05 & 54.4 & 1.33 & 60.4 & 1.48 & 36.2 & 0.885 & 166 & 4.04 \\
\hline & V4R3 & 47.45 & 36.1 & 0.761 & 49.5 & 1.04 & 57.5 & 1.21 & 33.6 & 0.708 & 160 & 3.35 \\
\hline \multirow{3}{*}{ Ref. [34] } & B500 & 23.9 & 17.0 & 0.710 & 24.7 & 1.03 & 25.4 & 1.06 & 5.10 & 0.213 & 15.1 & 0.631 \\
\hline & B1200 & 31.55 & 21.9 & 0.694 & 31.4 & 0.995 & 32.0 & 1.01 & 6.70 & 0.214 & 19.6 & 0.622 \\
\hline & B1800 & 45.85 & 30.9 & 0.673 & 43.2 & 0.942 & 43.1 & 0.940 & 10.0 & 0.218 & 28.2 & 0.614 \\
\hline \multirow{2}{*}{ Ref. [5] } & S2 & 46.65 & 52.2 & 1.12 & 49.7 & 1.07 & 45.5 & 0.976 & 30.3 & 0.649 & 97.2 & 2.08 \\
\hline & S3 & 48.3 & 42.3 & 0.877 & 51.4 & 1.07 & 56.0 & 1.16 & 27.8 & 0.576 & 94.1 & 1.95 \\
\hline \multirow{2}{*}{ Ref. [35] } & B2 & 63.9 & 59.1 & 0.925 & 74.9 & 1.17 & 83.3 & 1.30 & 36.4 & 0.542 & 69.9 & 1.04 \\
\hline & B5 & 65.5 & 51.4 & 0.785 & 67.5 & 1.03 & 76.5 & 1.17 & 41.5 & 0.610 & 66.2 & 0.973 \\
\hline \multirow{3}{*}{$\begin{array}{l}\text { Statistical } \\
\text { indicators }\end{array}$} & Average = & & & 0.863 & & 1.10 & & 1.17 & & 0.555 & & 1.90 \\
\hline & STD $=$ & & & 0.155 & & 0.119 & & 0.172 & & 0.259 & & 1.34 \\
\hline & $\mathrm{CoV}=$ & & & 0.180 & & 0.108 & & 0.147 & & 0.467 & & 0.702 \\
\hline
\end{tabular}

Note: $V_{p r e, 1}=$ shear force predicted by the proposed model with $s_{c}^{\min }$;

$V_{\text {pre, } 1.5}=$ shear force predicted by the proposed model with $1.5 s_{c}^{\mathrm{min}}$;

$V_{\text {pre, } 2}=$ shear force predicted by the proposed model with $2 s_{c}^{\min }$;

$V_{H-R}=$ shear force predicted by Hassan and Rizkalla's model [25]; and

$V_{A I}=$ shear force predicted by Al-Mahmoud et al.'s model [22]. 


\section{FIGURES}

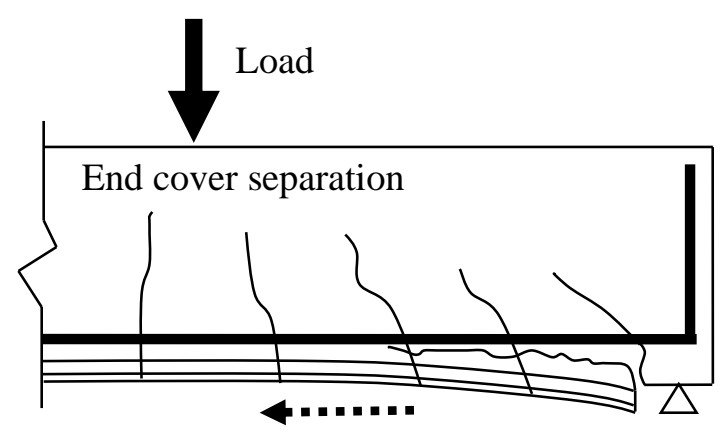

Fig. 1 Schematic of end cover separation

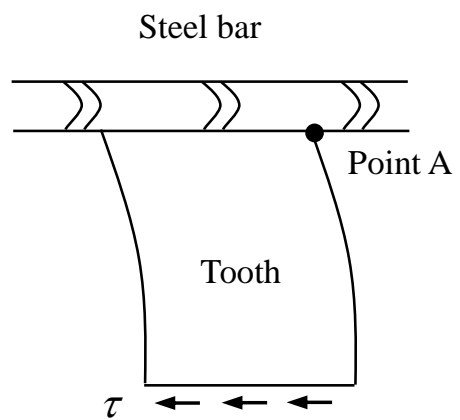

Fig. 2. Concrete tooth between two adjacent cracks

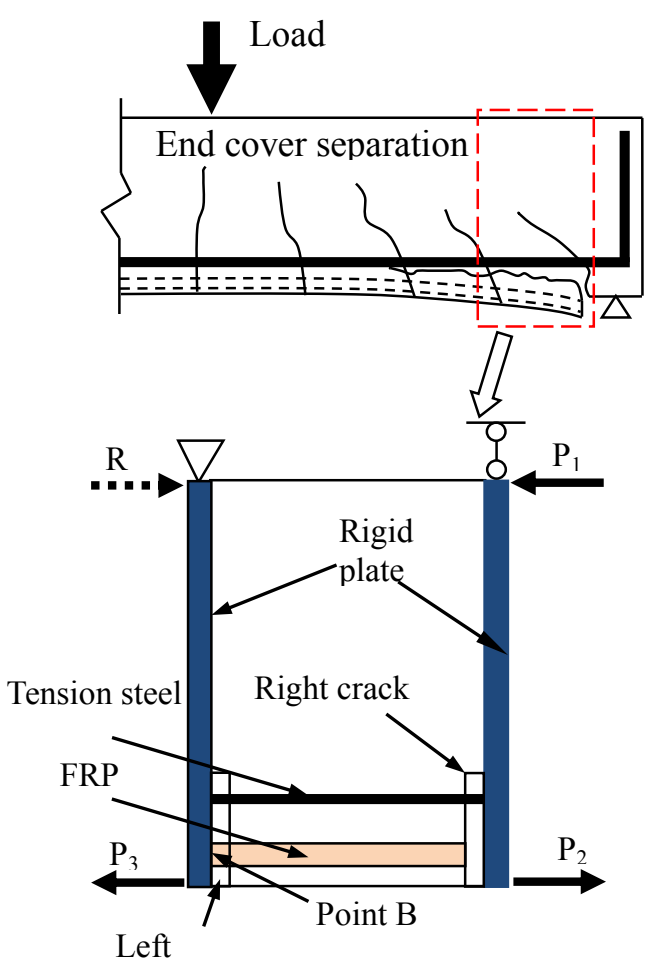

Fig. 3. Simplified finite element model 


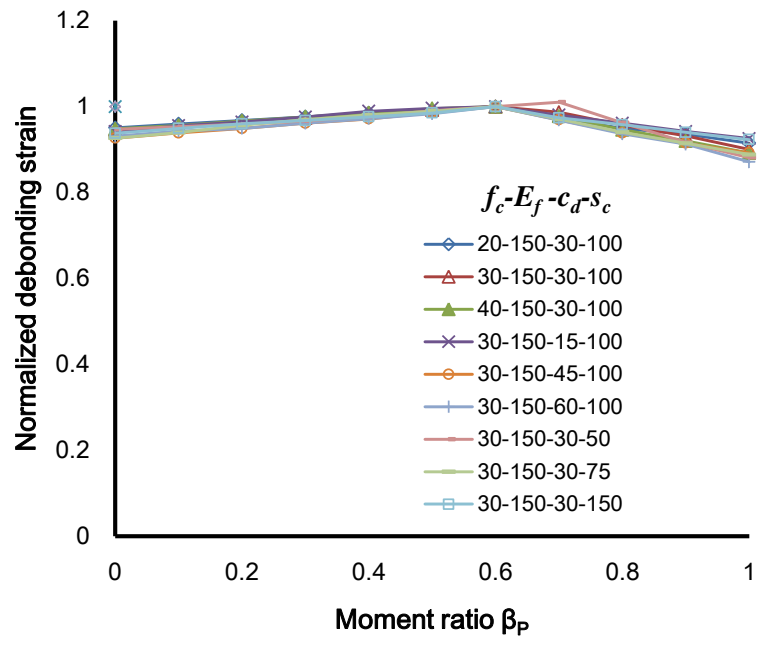

Fig. 4. Effect of moment ratio on normalized debonding strain

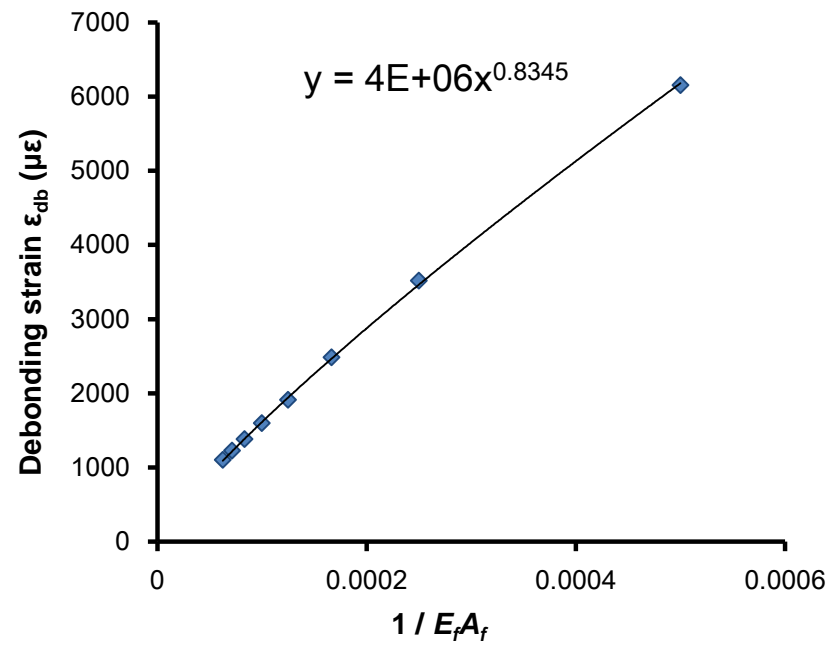

Fig. 5. Effect of axial rigidity of FRP on debonding strain

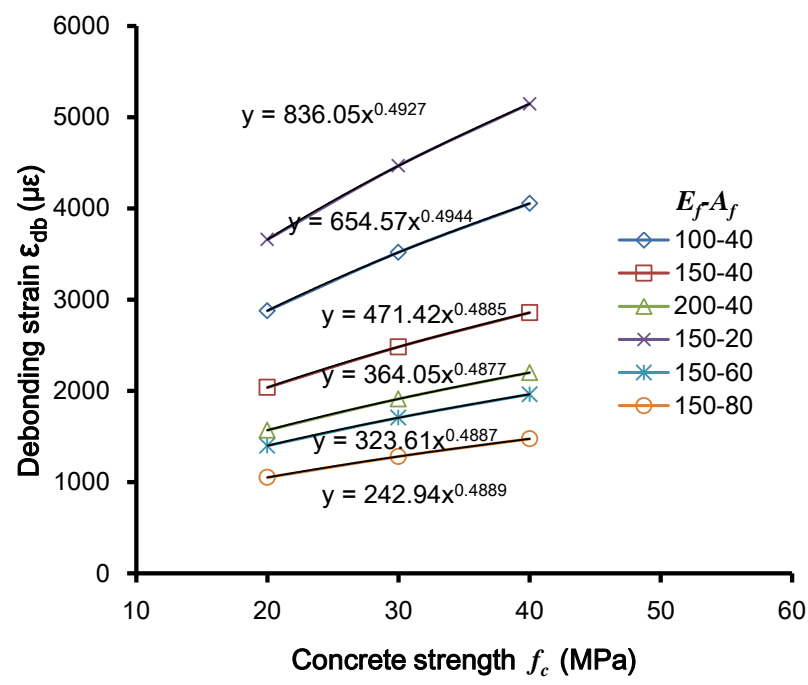

Fig. 6. Effect of concrete strength on debonding strain 


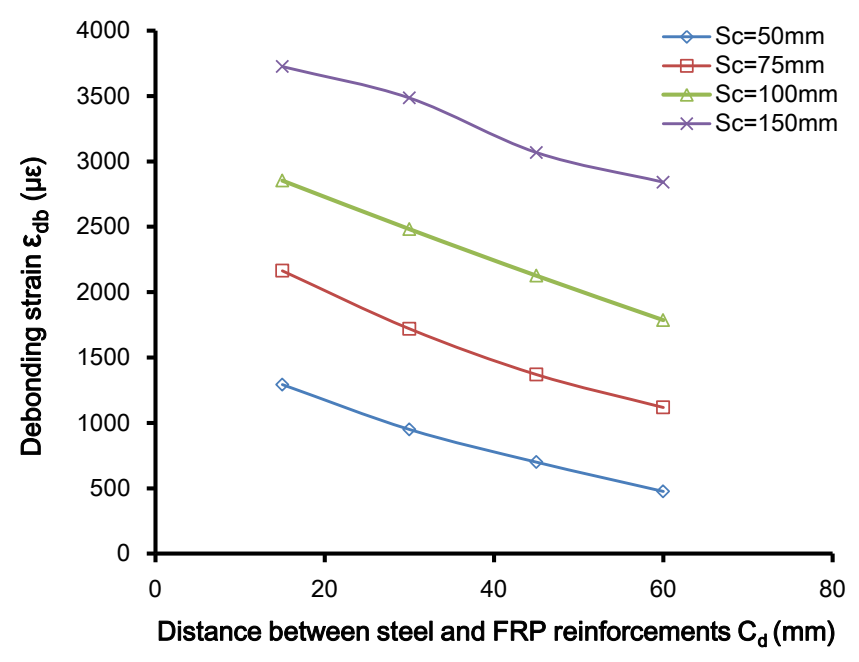

Fig. 7. Effect of distance between steel and FRP reinforcements on debonding strain

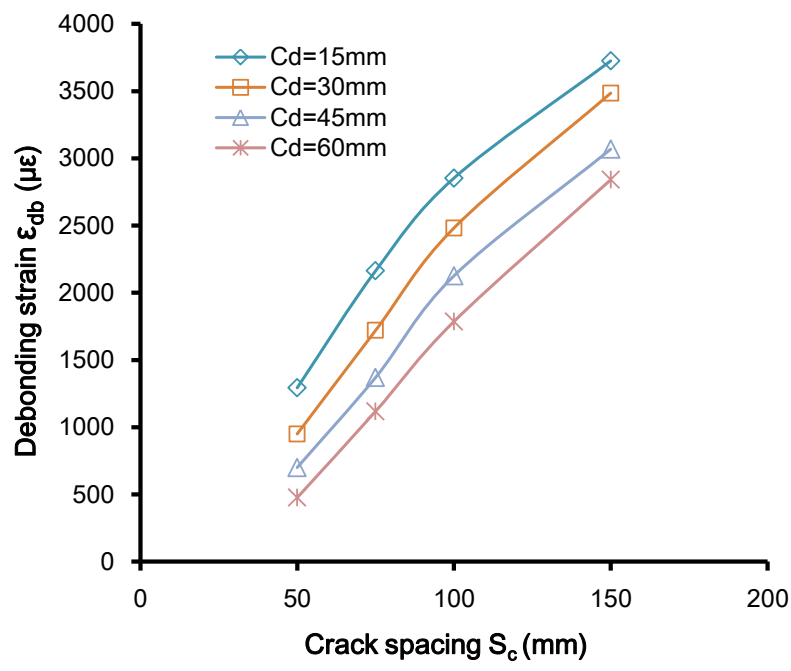

Fig. 8. Effect of crack spacing on debonding strain

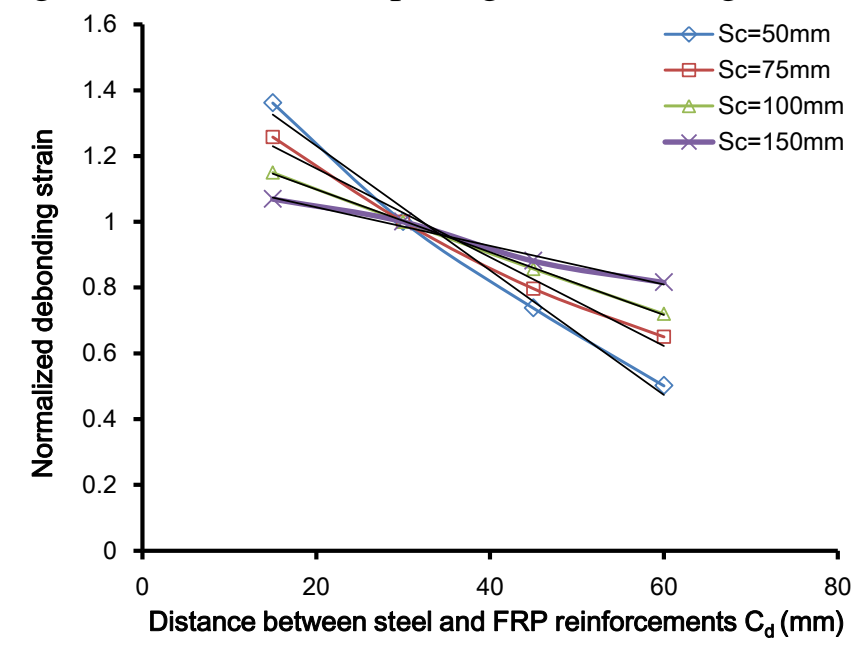

Fig. 9. Effect of distance between steel and FRP reinforcements on normalized debonding strain 


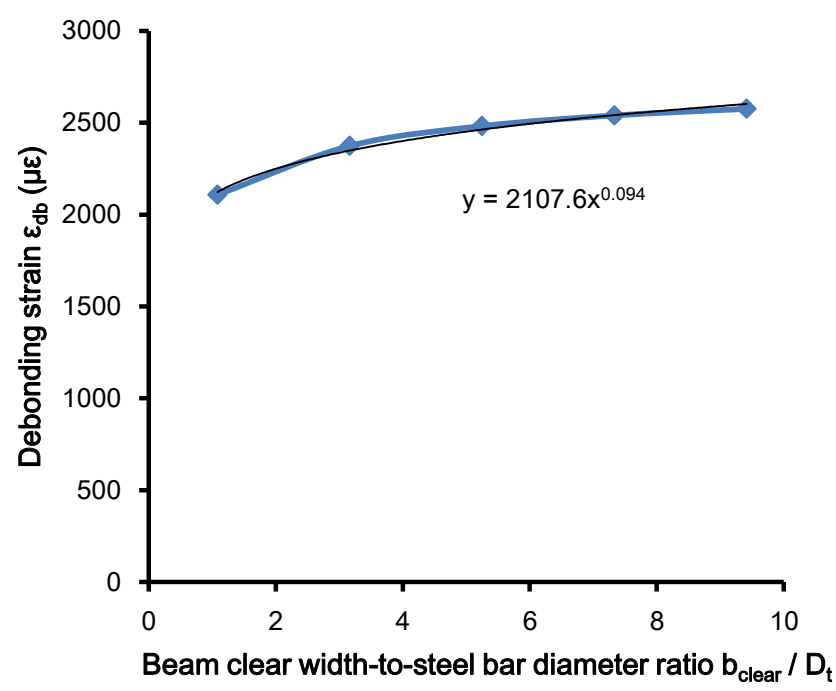

Fig. 10. Influence of beam clear width-to-steel bar diameter ratio on debonding strain

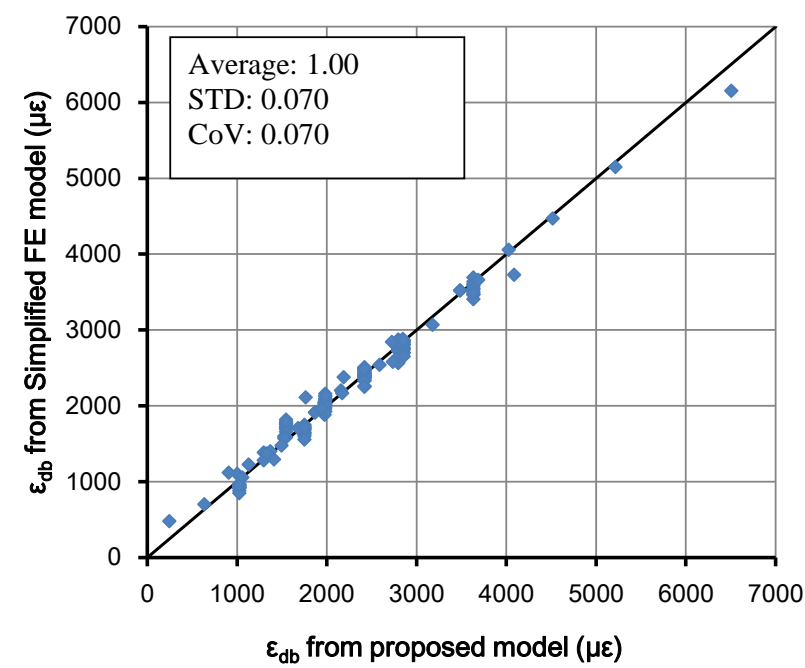

Fig. 11. Comparison of debonding strain between FE predictions and proposed strength model 


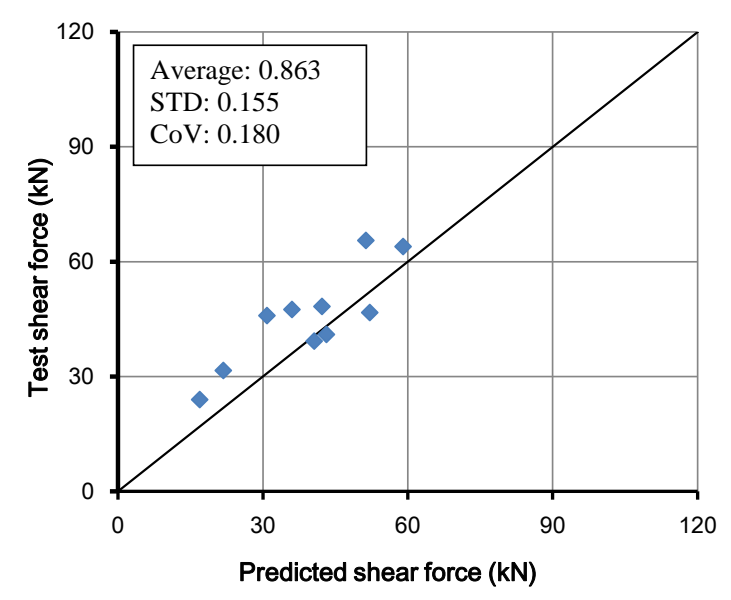

(a) Crack spacing $=s_{c}^{\text {min }}$

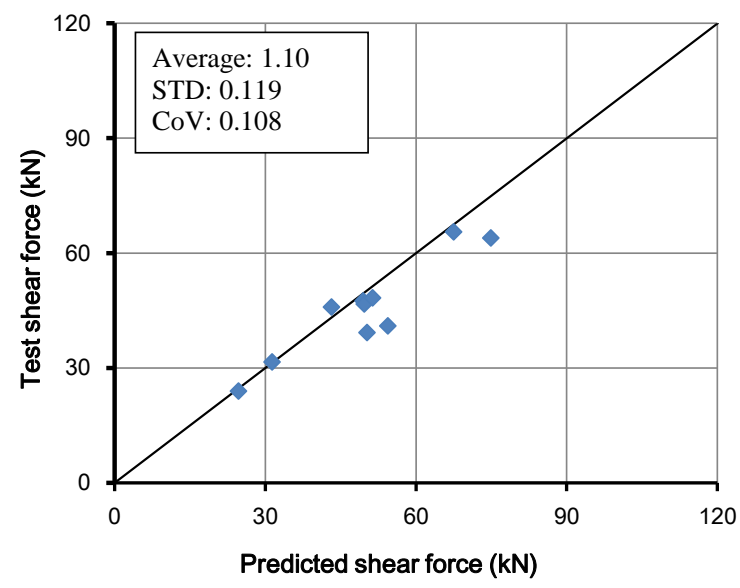

(b) Crack spacing $=1.5 \mathrm{~s}_{c}^{\mathrm{min}}$

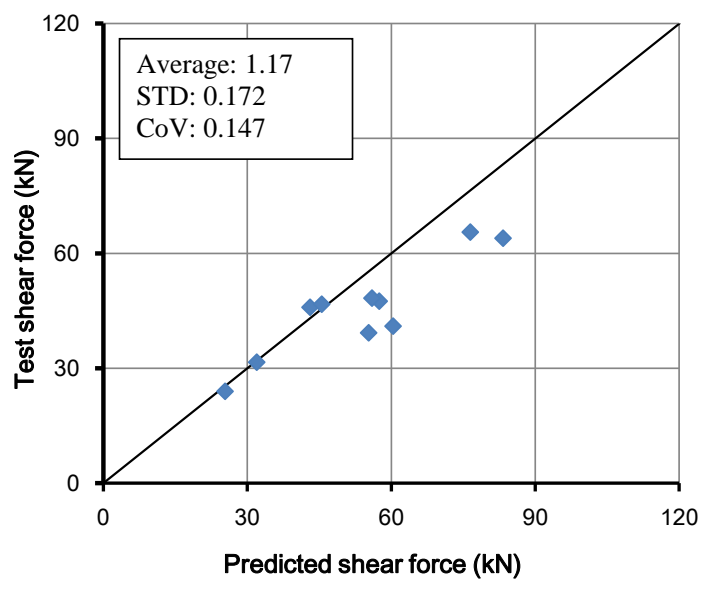

(c) Crack spacing $=2 s_{c}^{\min }$

Fig. 12. Comparison of shear force at debonding between tests and proposed strength model 


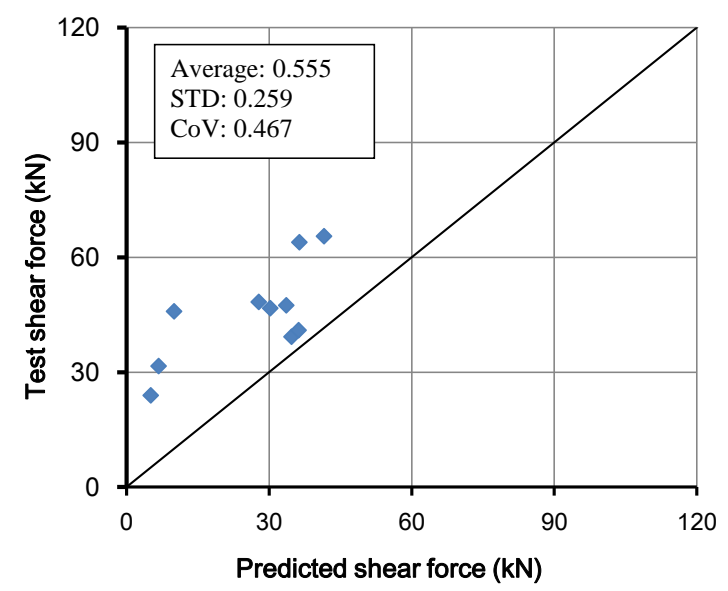

Fig. 13. Comparison of shear force at debonding between tests and Hassan and Rizkalla's model [25]

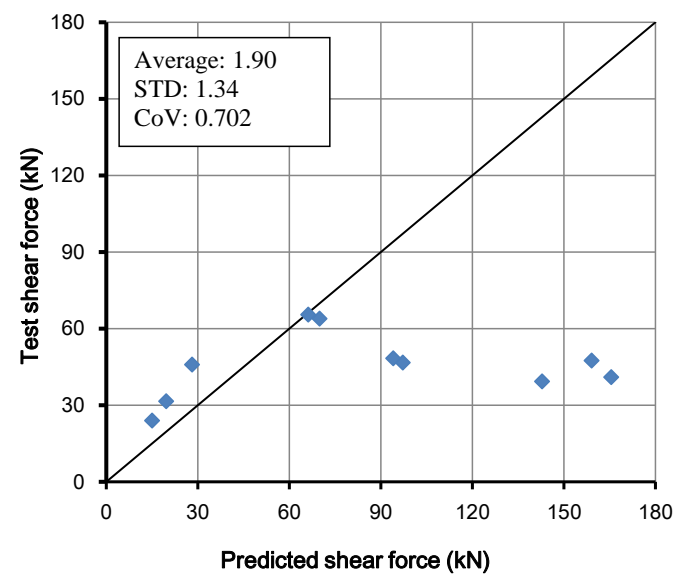

Fig. 14. Comparison of shear force at debonding between tests and Al-Mahmoud et al.'s model [22] 